\title{
Effect of arthroscopic techniques on joint volume in shoulder instability: Bankart repair versus capsular shift
}

\author{
Przemyslaw Lubiatowski $^{1,2}$ • Jan Długosz ${ }^{2}$ - Marta Ślęzak ${ }^{1,2} \cdot$ Piotr Ogrodowicz $^{1,2}$ • \\ Jakub Stefaniak $^{1,2}$. Joanna Walecka ${ }^{1,2} \cdot$ Leszek Romanowski $^{1}$
}

Received: 29 March 2016 / Accepted: 1 August 2016 / Published online: 19 August 2016

(C) The Author(s) 2016. This article is published with open access at Springerlink.com

\begin{abstract}
Purpose The evaluation of glenohumeral joint volume in both unstable (with/without laxity) and stable shoulders (subacromial impingement) and volume reduction potential of arthroscopic techniques: (labral anchor repair vs. capsular shift).

Methods Material was based on 133 patients: anterior shoulder instability without laxity (group I, $n=49$ ), with laxity (group II, $n=22$ ) and subacromial impingement (control group, $n=62$ ) operated in 2010-2011. Group I received arthroscopic Bankart repair, group; II - arthroscopic anterior capsular plication, control group - subacromial decompression. Joint volume was measured by fluid aspiration into the syringe via arthroscope, before and after procedure. Then volume reduction potential was calculated.

Results The following average values of initial joint volume were recorded: group I $-26.8 \mathrm{ml}$ group II $-43.7 \mathrm{ml}$ and the control group $-25.6 \mathrm{ml}$ with significant differences: impingement vs. instability + laxity $(p<0.00001)$, impingement vs. instability without laxity $(p=0.0001)$. There was no significant difference between groups I and II. Joint volume was significantly reduced after labral repair (by average of $37 \%$, $13.8 \mathrm{ml}, p<0.0001)$. Capsular shift led to an even greater and more significant volume decrease $(61 \%, 26.7 \mathrm{ml}, p<0.001)$. Joint volume in the control group was reduced only by $11 \%$, $3.8 \mathrm{ml}(p=0.046)$.
\end{abstract}

Jakub Stefaniak

przemyslaw.lubiatowski@rehasport.pl

1 Department of Traumatology, Orthopaedics and Hand Surgery, University of Medical Sciences in Poznan, Poznań, Poland

2 Rehasport Clinic, Poznań, Poland
Conclusions Patients with unstable shoulders have enlarged joint volume as compared to patients with subacromial impingement. Arthroscopic techniques lead to a significant joint volume reduction, with the most powerful effect for capsular shift.

Level of Evidence - Level 2.

Keywords Bankart repair · Capsular shift · Joint volume · Shoulder arthroscopy $\cdot$ Shoulder instability

\section{Introduction}

Shoulder instability, both traumatic and atraumatic, has been attributed to various factors [1-5]. Most of them include the failure of a passive stabilization mechanism in the part of the capsulolabral complex that includes labral or ligamentous tears, capsular stretching and redundancy [1-3].

In many cases of shoulder instability, particularly in the multidirectional shoulder instability (MDI), the initial treatment is based on a rehabilitation program. In case of failure, surgical treatment, such as shoulder arthroscopy, is recommended [6]. Arthroscopic techniques have been used to treat the problems successfully for many years. Repair with application of anchors is a standard treatment for patients with a labral tear without significant bone loss. In case of failed conservative treatment for atraumatic instability with capsular laxity an arthroscopic approach is an option. Open capsular shift had been a golden standard in the past, later replaced by arthroscopic techniques [7-11]. Capsular shift is intended to decrease volume, thus constraining the joint. The potential to reduce the joint volume has been studied before on a cadaveric shoulder model [12-21], showing that open techniques allow for higher volume reduction (40-50\%) than arthroscopic techniques (30-40\%). However, a cadaveric shoulder may 
not reflect a life scenario of the unstable shoulder in a much younger population and different joint capacity despite the fact that various modifications of arthroscopic techniques have been published to make either capsular shift or plication. To our best knowledge there has been no report on volume reduction effect in the clinical in vivo scenario in arthroscopic stabilization techniques apart from our technical report on arthroscopic capsular shift [22]. Such evaluation would provide proper knowledge of how the surgical techniques affect the joint biomechanics and the anatomy of the glenohumeral joint [12-21].

We presumed that shoulders with instability would have enlarged joint volume in comparison to that in noninstability patients. Our previous report showed that capsular shift decreased the joint volume [22]. We also hypothesized that the volume reduction provided by capsular shift would be larger than in the case of labral repair. The aim of this study was to evaluate the glenohumeral joint volume in unstable shoulders (with or without laxity) with comparison to stable shoulders (subacromial impingement) and to evaluate volume reduction potential of arthroscopic techniques (labral repair vs. capsular shift).

\section{Materials and methods}

The cohort study is based on shoulder volume measurement during arthroscopy in prospective consecutive cases. The clinical material included 20 patients in a pilot reliability study and 133 patients in the main study with instability of the shoulder joint and subacromial impingement (as control) who underwent a shoulder arthroscopy procedure in our institutions during the period of 2010-2011. The study was approved by the Bioethical Committee of the University of Medical Sciences in Poznan and all the patients signed informed consent.

The instability patients were classified according to Gerber's classification, as unidirectional anterior shoulder instability without laxity-B2 (group I, $n=49$ ) and unidirectional or multidirectional instability with laxity (B3 and B5) (group II, $n=22$ ). Inclusion criteria for group I were: B2 instability type, labral tear, arthroscopic labral repair and consent to take part in the study. Inclusion criteria for group II were: B3 or B5 instability type, arthroscopic capsular shift and consent to take part in the study. Patients with previous shoulder procedures and other shoulder lesions (cuff tear, arthritis) were excluded from either group. The patients were qualified for the control group if they were operated on with arthroscopic decompression for subacromial impingement and agreed to participate in the study. Exclusion criteria for the group included: glenohumeral pathology on arthroscopy of previous imaging, previous surgery and other procedures performed during surgery other than subacromial decompression.

Shoulder laxity was diagnosed if both the Gagey hyperabduction test and a sulcus sign had been positive and external rotation with the arm at the side was greater than $85^{\circ}$. Control shoulders included patients after arthroscopic procedure due to subacromial impingement (subacromial decompression) without rotator cuff tear (control, $n=62$ ). Basic demographic data are depicted in Table 1.

The control group was significantly older than groups I and II. No age difference was found between both instability groups.

The patients in group I received typical labral repair with three anchors placed anteriorly to fix the labrum to the anterior margin of the glenoid. Anchors were placed at 5.30, 4.30 and 2.30 positions as represented at the clock face view of the right glenoid. The labral lesions included the Bankart or Perthes type. Excluded from the study were patients with other lesions which would involve other labral lesions (SLAP, HAGL, ALPSA) or significant glenoid defects ( $>20 \%$ on arthroscopic evaluation acc. to the Burkhart method [23]). The capsular shift group received arthroscopic anterior capsular shift according to the previously described technique [9]. The control group underwent intra-articular diagnostic arthroscopy followed by standard subacromial decompression.

The pilot study to verify the reliability of the measuring technique was performed in a separate group of 20 consecutive patients who had shoulder arthroscopy and "water-tight" shoulders. The average age of the patients in the pilot group was 38 ( \pm 13.7 ; min. 20, max. 64). Indications for arthroscopy included: labral tears $(n=15)$, subacromial impingement $(n=5)$.

\section{Volume measurement}

All measurements of the volume were performed before and after the arthroscopic procedure. All patients were operated on

Table 1 Demographic data of the patients in the study groups. n.s. - non significant, $p>0.05$

\begin{tabular}{|c|c|c|c|c|}
\hline & Group I & Group II & Control & Statistical analysis \\
\hline Age (avg./min./max.) & $27 / 16 / 45$ & $24 / 17 / 37$ & $47 / 24 / 83$ & $\begin{array}{l}\text { Group I vs group II- n.s., control group vs. group I and II }(\mathrm{p}<0.001) \\
\text { (Kruskal-Wallis Anova) }\end{array}$ \\
\hline Sex (male/female) & $44 / 5$ & $13 / 9$ & $31 / 31$ & $\begin{array}{l}\text { Significantly more males in group I vs. group II }(\mathrm{p}<0.01) \text { and vs. control }(\mathrm{p}<0.001) \text {, } \\
\text { no significant difference between group II and control; Chi-square test. }\end{array}$ \\
\hline
\end{tabular}


in the beach-chair position. The first volume recording was performed after introducing two cannulas into separate portals (mid-anterior and superolateral) for the instability patients. Cannulas $(7 \mathrm{~mm})$ were sealed with obturators. No anterior portals were done in the control group. The glenohumeral joint was filled-up with saline, using an arthroscopic pump with the fixed pressure of $90 \mathrm{mmHg}$ and the flow at $1.5 \mathrm{l} /$ min. All the remaining air was carefully removed from the glenohumeral joint. Then the influx was closed and all saline from the joint was aspirated into a $50 \mathrm{ml}$ syringe, through the arthroscope valve, under visual control (Fig. 1). The measurements were repeated to receive a mean value of two attempts. The final recordings were performed after the procedures, depending on the study group (respectively, labral repair, capsular shift, subacromial decompression). For the instability group cannulas were sealed again with obturators. The remaining air was cleared out from the joint. The joint was refilled with the same pressure conditions and then one valve was blocked. All the fluid was aspirated again into a $50 \mathrm{ml}$ syringe. Two attempts were performed to receive a mean volume value. The same measurements were taken for the impingement group, except that no cannulas were used and no anterior portals performed.

Volume reduction potential was calculated by dividing the difference of the initial (before procedure) and final (after procedure) volume by the initial volume of the joint. The value was multiplied by 100 to represent "\%".

For the subacromial impingement group the measurements were performed before and after subacromial decompression.

The pilot study included reliability assessment of the joint volume measurements. At first, the test-retest measurements were performed in each patient, as described earlier with the same set-up. The joint was filled with saline under the same parameters and then the whole volume was aspirated into a $50 \mathrm{ml}$ syringe. The procedure was performed twice (test and re-test) and the values were recorded. Then the known and recorded volume aspirated into the syringe during the second measurement (re-test) was injected to the joint (injected volume). The injected saline was re-aspirated into syringe and the value recorded (aspirated volume). This part was performed in order to verify the risk of leakage.
Statistical analysis was performed by using StatPlus mac 2009 (AnalystSoft) and AgreeStat2015.5 for Mac (Advanced Analytics). Normality tests were performed for the analysis of data distribution by using the Kolmogorov-Smirnov test. The non-parametric Wilcoxon, Kruskal-Wallis one-way analysis of variance by ranks with Dunn's post hoc test and chi-square tests was further used when the test proved against normality. The t-student test and analysis of variance (ANOVA) with Fisher's least significant difference post hoc test were performed for normal distribution data. The $p$ value $<0.05$ was set as the level of statistical significance. For the pilot study intraclass correlation coefficient was calculated in both parts of the validation.

Level of Evidence - Level 2.

\section{Results}

The pilot study showed that measuring the volume of the glenohumeral joint is a reliable method. The risk of leakage and a possible systematic error of underestimation of the real joint volume was shown to be negligible (Table 2). There was an almost perfect positive linear relationship between the measurements.

The results of the volume measurements and volume reduction are presented in Figs. 2, 3 and 4 and Table 3. Female shoulders were significantly less voluminous than male in all groups. Initial joint volume was largest for both of the instability groups and significantly greater than in the impingement patients. No significant difference could be seen between the groups with and without laxity when both sexes were combined. However, when calculations were performed separately for the sexes, group II (laxity) would have the largest volumes, followed by group I (Bankart) and, finally, the impingement group had the lowest values in males and females.

There was a significant volume reduction when labral repair had been performed (by average of $37 \%$ ) (Fig. 3). Capsular shift led to an even greater and more significant volume decrease (61\%). Joint volume was reduced by only $11 \%(p=0.046)$ in the control group (measured twice before and after subacromial decompression). The results were compared and analysed statistically (Table 3).
Fig. 1 Measurement of shoulder volume during arthroscopic procedure. The syringe is attached to the arthroscope outflow tap (a). All the fluid is aspirated into the syringe while the inflow and cannula are obliterated

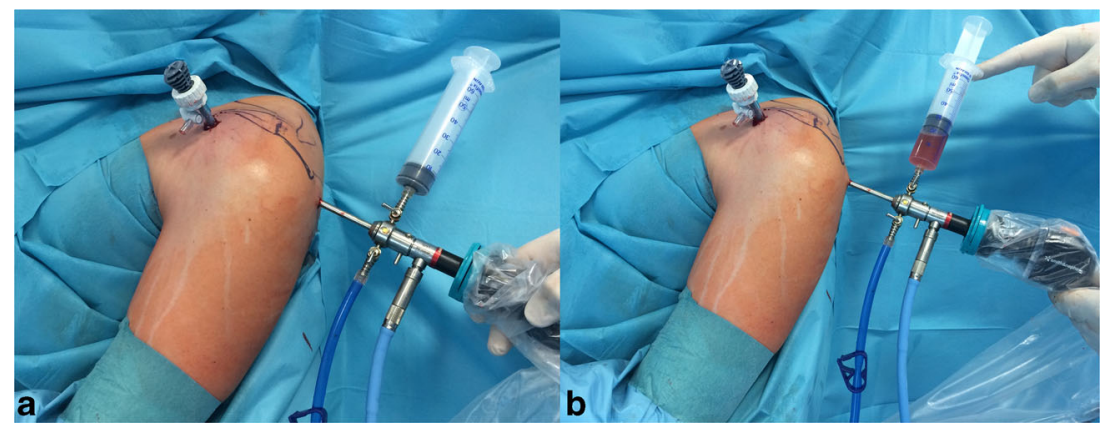


Table 2 Result of pilot reliability study

\begin{tabular}{lllllll}
\hline & Test $(\mathrm{ml})$ & Retest $(\mathrm{ml})$ & Difference $(\mathrm{ml})$ & Injected volume $(\mathrm{ml})$ & Aspirated volume (ml) & Difference (ml) \\
\hline Average volume & 33.1 & 33.1 & 0.1 & 32.9 & 32.7 & 0.2 \\
SD & 8.8 & 8.9 & 0.7 & 8.9 & 8.8 & 0.7 \\
T- student & $\mathrm{p}=0.65$ & & $\mathrm{p}=0.19$ & 0,$9965 ;$ meaned $0.9982, \mathrm{~F} 605.841, \mathrm{p}<0.0001$ \\
ICC & $0.9962 ;$ meaned $0.9981, \mathrm{~F}$ 501.9661, $\mathrm{p}<0.0001$ & & \\
\hline
\end{tabular}

\section{Discussion}

The hypotheses of our study included enlarged glenohumeral joint volume in instability patients as compared to the impingement group and joint volume reduction following both arthroscopic stabilization and capsular shift. The purpose of the presented study was to evaluate the effect of volume reduction of two stabilization arthroscopic techniques (labral repair and capsular shift). For comparison, the "normal" glenohumeral joint of subacromial impingement syndrome was used. For the latter, patient's joint volume was reevaluated following the decompression to estimate the influence of possible shoulder swelling of the final result. This was mostly intended to deduct the possible influence of the swelling of the surrounding tissue and the external restriction of volume not related to tissue repair. The results of the study showed enlarged glenohumeral joint volume in unstable shoulders. Unstable shoulders with laxity were significantly larger in comparison to those without laxity in our cohort only when the females and males were calculated separately. Any procedure in the study led to reduced volume, with greatest potential of capsular shift (61\%), followed by labral repair $(37.2 \%)$ and subacromial decompression (11\%).

The exact role of joint volume in shoulder stability and function is not well understood. Limited joint volume, as described by Matsen, contributes to shoulder stability [1] and maintaining the negative pressure inside the joint [4, 24-26]. This mechanism was based on the glenohumeral contact area, a relatively limited volume of the sealed joint and material properties of the capsule $[2,27]$. The stability effect induced by intra-articular pressure does not seem to work efficiently in the case of the unstable shoulder [24], most probably due to the lack of capsular confinement [25]. We could assume that both the repair of the capsulolabral complex and capsular shift have multiple effects on the biomechanics of the joint, which includes a reduction of joint volume and the tensioning of the capsule.

Normal joint volume has been estimated by Neviaser [28] as $28-35 \mathrm{ml}$, which falls slightly above our control group and below both the instability groups of our study. It was assumed by Itoi [2] that the unstable shoulder has enlarged volume. Yet, this has not been definitely proven so far. The observation was first suggested by Reeves et al. in arthrographic studies [29], but it was later contradicted by Sperber and Wredmark [30]. The latter did not find the difference of volume while comparing unstable and stable shoulders in the same individuals (average of $27 \mathrm{ml}$ in both groups), stating that the recurrent dislocation did not lead to increased joint volume. Dietz et al. published similar results, making comparisons of joint volumes of first-time dislocators, recurrent dislocators and normal glenohumeral joints (impingement syndrome), relating the joint volumes to the body surface area [19]. However, the authors mentioned that the instability group had the average volume of $50.7 \mathrm{ml}$ in comparison to $38.3 \mathrm{ml}$ in impingement patients. That was also the case in our study. We have shown that joint volumes in both instability groups (no-laxity $37 \mathrm{ml}$ and laxity $44 \mathrm{ml}$ ) were significantly larger than in the impingement group (26 ml), thus confirming Itoi's assumption [2]. The impingement group was evidently older than the other two groups. We suppose that joint volume decreases
Fig. 2 Results of glenohumeral initial volume measurements in females and males in all study groups (ml)




Fig. 3 Results of glenohumeral initial and final volume measurements in all study groups (ml) (females and males combined)



with age, and is also accompanied by increased joint stiffness. No such data could be found for the shoulder. However, decreased tissue elasticity and increased stiffness have been reported in connection with age in relation to ligaments and tendons [31-33]. Older age could thus be one of the explanations of decreased risk of recurrent dislocation [34].

Several techniques of capsular shift (open and arthroscopic) have been presented in literature for the treatment of shoulders with laxity and multidirectional instability $[1,7-11,15$, 22]. Their volume reduction potential has been evaluated in cadavers. Open procedures can reduce the volume by 46$66 \%$ [12, 14-17]. Arthroscopic techniques have been found to have less potential for decreasing the volume - by 16-19\% $[13,15,21]$. However, in the clinical scenario, arthroscopic shift is clearly more powerful, as we managed to show in this study - with $61 \%$ volume reduction. Volume reduction can also be anticipated when labral repair is performed. Tissue management always involves some degree of capsular plication. No volume reduction effect has been reported on the labral repair alone in literature. Some reduction has also been observed in the control group. We assumed that it might be related to tissue swelling during the time of the arthroscopy.

In the case of Bankart lesions, by repairing the labrum, normal anatomy and biomechanics are restored (bumper, suction cup, ligament tensioning) $[1,3,24,35]$. Decreasing the joint volume that accompanies labral repair might be a supporting mechanism by enhanced joint vacuum. Retention of tissues may also affect proprioception, this way improving the dynamic control of the joint. Joint proprioception has been found abnormal in shoulder instability, and restored following labral repair [36].

Another issue to be remembered is that over-tensioning during the instability procedure may lead to joint stiffness. This is important not only during the capsular shift. As has been shown in our study, a significant reduction of joint volume can be expected in Bankart labral too. One should bear it in mind when dealing with patients without laxity, or when laxity is not the leading factor in avoiding postoperative shoulder stiffness [37]. Cadaveric studies have shown that capsular shrinkage and reducing the joint volume also decrease the glenohumeral translation and rotational movements [18].

\section{Limitations of the study}

There are some limitations of the study. One might be related to the technique of performing measurements following the repair, as a certain volume of saline could be lost due to the leakage via working portals and areas of labral repair. Therefore a pilot validation study was performed. Repeatability was very high and we have shown that in the measuring setup there is no risk of losing fluid. To our best knowledge this is the first attempt to validate volume measurement in vivo. Cadaver studies have
Fig. 4 Results of volume reduction in all study groups (\%)

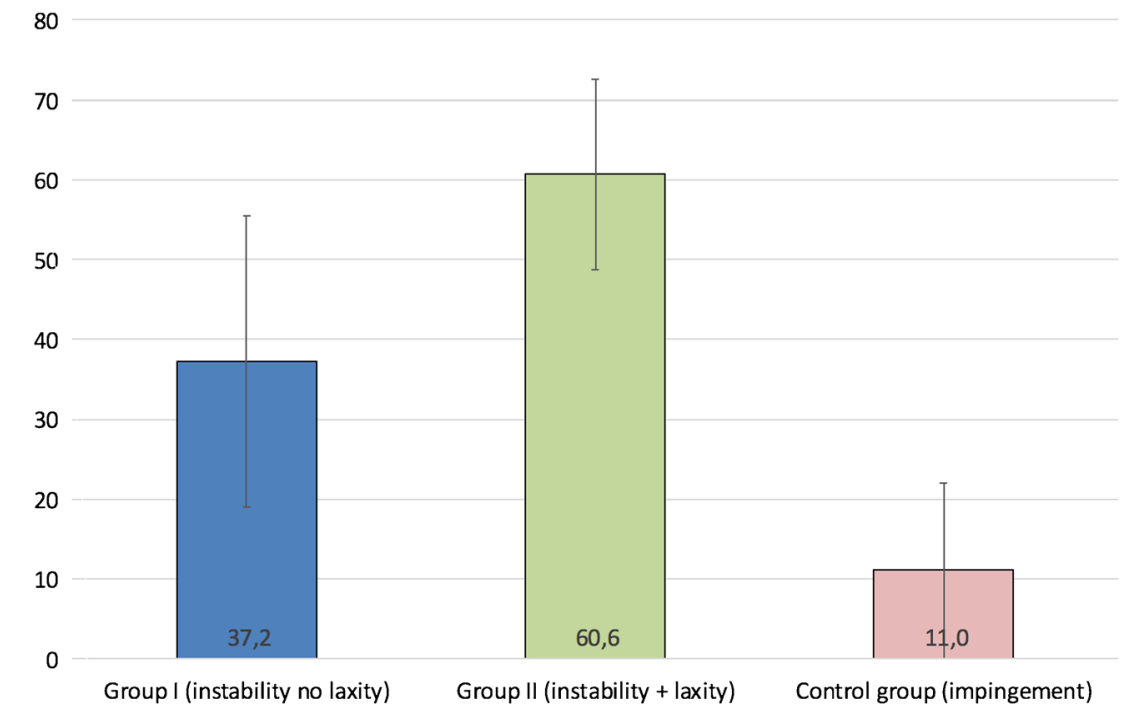

80 
Table 3 Comparisons and statistical significance

\begin{tabular}{|c|c|c|c|}
\hline Correlations & & $\mathrm{P}$ value & Statistical test \\
\hline \multirow[t]{2}{*}{ comparison of initial volume (both sexes combined) } & $\begin{array}{l}\text { group I vs. control group } \\
\text { group II vs. control group }\end{array}$ & $\begin{array}{l}0.0001 \\
<0.00001\end{array}$ & \multirow[t]{2}{*}{ Kruskal-Wallis test } \\
\hline & group I vs. group II & 0.35 & \\
\hline \multirow[t]{2}{*}{ Initial volume in female vs. male } & $\begin{array}{l}\text { Group I } \\
\text { Group II }\end{array}$ & $\begin{array}{l}0.038 \\
0.035\end{array}$ & \multirow[t]{2}{*}{ t-test } \\
\hline & Control & 0.0002 & \\
\hline \multirow[t]{2}{*}{ comparison of initial volume in females } & $\begin{array}{l}\text { group I vs. control group } \\
\text { group II vs. control group }\end{array}$ & $\begin{array}{l}0.039 \\
<0.0001\end{array}$ & \multirow[t]{2}{*}{ ANOVA } \\
\hline & group I vs. group II & 0.04 & \\
\hline \multirow[t]{2}{*}{ comparison of initial volume in males } & $\begin{array}{l}\text { group I vs. control group } \\
\text { group II vs. control group }\end{array}$ & $\begin{array}{l}0.0004 \\
<0.0001\end{array}$ & \multirow[t]{2}{*}{ ANOVA } \\
\hline & group I vs. group II & 0.013 & \\
\hline \multirow[t]{2}{*}{ comparison of the volume following procedure } & $\begin{array}{l}\text { group I vs. control group } \\
\text { group II vs. control }\end{array}$ & $\begin{array}{l}0.93 \\
0.001\end{array}$ & \multirow[t]{2}{*}{ Kruskal-Wallis test } \\
\hline & group I vs. group II. & 0.019 & \\
\hline \multirow[t]{2}{*}{ comparison of volume reduction } & $\begin{array}{l}\text { group I vs. control group } \\
\text { group II vs. control }\end{array}$ & $\begin{array}{l}<0.0001 \\
<0.0001\end{array}$ & \multirow[t]{2}{*}{ Kruskal-Wallis test } \\
\hline & group I vs. group II. & $<0.0001$ & \\
\hline $\begin{array}{l}\text { instability-no laxity } \\
\text { instability-laxity }\end{array}$ & $\begin{array}{l}\text { comparison of initial vs. following procedure in group I } \\
\text { comparison of initial vs. following procedure in group II }\end{array}$ & $\begin{array}{l}<0.0001 \\
<0.001\end{array}$ & \multirow[t]{2}{*}{ Wilcoxon test } \\
\hline internal impingement & comparison of initial vs. following procedure in control group & 0.046 & \\
\hline
\end{tabular}

used thicker solutions (soap). However, the results of cadaver studies have serious flaws such as human tissues stiffness, or failure to genuinely represent the clinical situation (age, degenerative changes, stiffness). The in vivo study comparing different methods (direct-needle-syringe, MR and US) was carried out by Lubovitz et al. [12]. They have shown similar results with direct and MR measurement and hypothesised that despite possible extravasation of the fluid, direct measurement is possible.

Another limitation is the influence of tissue swelling on the volume, which certainly cannot be avoided. Therefore, we also measured the volume in the impingement group again, after the procedure had been accomplished. That resulted in an $11 \%$ decrease in volume and may represent the effect of the swelling. A further limitation is the heterogeneity of the study groups. The impingement group was significantly older than both instability groups. There were also more males than females in group I (instability without laxity). Unfortunately, those values could not be controlled. This was a prospective study of consecutive cases. The control group could not be obtained in any other way, since evaluating the healthy contralateral shoulder was not ethically accepted.

\section{Conclusions}

Unstable shoulder seems to have enlarged joint volume as compared to subacromial impingement. Arthroscopic techniques for shoulder instability (both labral repair, and capsular shift) lead to a significant joint volume reduction in vivo, with the most powerful effect for capsular shift.

Open Access This article is distributed under the terms of the Creative Commons Attribution 4.0 International License (http:// creativecommons.org/licenses/by/4.0/), which permits unrestricted use, distribution, and reproduction in any medium, provided you give appropriate credit to the original author(s) and the source, provide a link to the Creative Commons license, and indicate if changes were made.

\section{References}

1. Matsen FA (2009) Mechanics of glenohumeral stability. In: Rockwood CA, Matsen FA (eds) The shoulder, 4th edn. Saunders, Philadelphia, pp 629-651

2. Itoi E (2004) Pathophysiology and treatment of atraumatic instability of the shoulder. J Orthop Sci 9:208-213

3. Motzkin NE, Itoi E, Morrey BF, An KN (1998) Contribution of capsuloligamentous structures to passive static inferior glenohumeral stability. Clin Biomech 13(1):54-61

4. Kumar VP, Balasubramaniam P (1985) The role of atmospheric pressure in stabilising the shoulder. An experimental study. J Bone Joint Surg (Br) 67(5):719-21

5. Alexander S, Southgate DFL, Bull AMJ, Wallace AL (2013) The role of negative intraarticular pressure and the long head of the biceps tendon on passive stability of the glenohumeral joint. J Should Elbow Surg 22:94-101

6. Kiss J, Damrel D, Mackie A, Neumann L, Wallace WA (2001) Non-operative treatment of multidirectional shoulder instability. Int Orthop (SICOT) 24:354-357. doi:10.1007/s002640000202 
7. Cicak N, Klobucar H, Bicanic G, Trsek D (2005) Arthroscopic extracapsular plication to treat multidirectional instability of the shoulder. Arthroscopy 21(10):1278

8. Sekiya JK (2005) Arthroscopic labral repair and capsular shift of the glenohumeral joint: technical pearls for a multiple pleated plication through a single working portal. Arthroscopy 21(6):766

9. Wiley WB, Goradia VK, Pearson SE (2005) Arthroscopic capsular placation- shift. Arthroscopy 1:119-21

10. Wolf EM, Eakin CL (1998) Arthroscopic capsular placation for posterior shoulder instability. Arthroscopy 14(2):153-63

11. Ahmad CS, Wang VM, Sugalski MT, Levine WN, Bigliani LU (2005) Biomechanics of shoulder capsulorrhaphy procedures. J Should Elbow Surg 14(1S):12S-18S

12. Lubowitz J, Bartolozzi A, Rubinstein D et al. (1996) How much does inferior capsular shift reduce shoulder volume? Clin Othop Relat Res;(328):86-90

13. Flanigan DC, Forsythe T, Orwin J, Kalpan L (2006) Volume analysis of arthroscopic capsular shift. Arthroscopy 22(5):528-33

14. Wiater JM, Vibert BT (2007) Glenohumeral joint volume reduction with progressive release and shifting of the inferior shoulder capsule. J Should Elbow Surg 16(6):810-4

15. Miller MD, Larsen KM, Luke T, Leis HT, Plancher KD (2003) Anterior capsular shift volume reduction: an in vitro comparison of 3 techniques. J Should Elbow Surg 12(4):350-4

16. Cohen SB, Wiley W, Goradia VK, Pearson S, Miller MD (2005) Anterior capsulorrhaphy: an in vitro comparison of volume reduction-arthroscopic plication versus open capsular shift. Arthroscopy 21(6):659-64

17. Luke TA, Rovner AD, Karas SG, Hawkins RJ, Plancher KD (2004) Volumetric change in the shoulder capsule after open inferior capsular shift versus arthroscopic thermal capsular shrinkage: a cadaveric model. J Should Elbow Surg 13(2):146-9

18. Victoroff BN, Deutsch A, Protomastro P, Barber JE, Davy DT (2004) The effect of radiofrequency thermal capsulorrhaphy on glenohumeral translation, rotation, and volume. J Should Elbow Surg 13(2):138-45

19. Dietz SO, Bartl C, Magosch P, Lichtenberg S, Habermeyer P (2006) Intra-articular volume assessment in glenohumeral instability. Knee Surg Sports Traumatol Arthrosc 14(2):189-92

20. Lino W Jr, Belangero WD (2006) Labrum repair combined with arthroscopic reduction of capsular volume in shoulder instability. Int Orthop 30(4):219-23

21. Karas SG, Creighton RA, DeMorat GJ (2004) Glenohumeral volume reduction in arthroscopic shoulder reconstruction: a cadaveric analysis of suture plication and thermal capsulorrhaphy. Arthroscopy 20(2):179-84

22. Lubiatowski P, Ogrodowicz P, Wojtaszek M, Bręborowicz M, Długosz J, Romanowski L (2012) Arthroscopic capsular shift technique and volume reduction. Eur J Orthop Surg Traumatol 22(6):437-441

23. Burkhart SS, De Beer JF (2000) Traumatic glenohumeral bone defects and their relationship to failure of arthroscopic Bankart repairs: significance of the inverted-pear glenoid and the humeral engaging Hill-Sachs lesion. Arthroscopy 16(7):677-94

24. Habermeyer P, Schuller U, Wiedemann E (1992) The intra-articular pressure of the shoulder: an experimental study on the role of the glenoid labrum in stabilizing the joint. Arthroscopy 8(2):166-72

25. Itoi E, Motzkin NE, Browne AO, Hoffmeyer P, Morrey BF, An KN (1993) Intraarticular pressure of the shoulder. Arthroscopy 9(4): 406-13

26. Unsworth A, Dowson D, Wright V (1971) 'Cracking joints'. A bioengineering study of cavitation in the metacarpophalangeal joint. Ann Rheum Dis 30(4):348-58

27. Levick JR (1983) Joint pressure-volume studies: their importance, design and interpretation. J Rheumatol 10(3):353-7

28. Neviaser JS (1962) Arthrography of the shoulder joint: study of the findings in adhesive capsulitis of the shoulder. J Bone Joint Surg Am 44(7):1321-59

29. Reeves B (1966) Arthrography of the shoulder. J Bone Joint Surg (Br) 48(3):424-35

30. Sperber A, Wredmark T (1994) Capsular elasticity and joint volume in recurrent anterior shoulder instability. Arthroscopy 10(6):598 601

31. Barros EM, Rodrigues CJ, Rodrigues NR, Oliveira RP, Barros TE et al (2002) Aging of the elastic and collagen fibers in the human cervical interspinous ligaments. Spine J 2(1):57-62

32. Narici MV, Maffulli N, Maganaris CN (2008) Ageing of human muscles and tendons. Disabil Rehabil 30(20-22):1548-54. doi:10.1080/09638280701831058

33. O'Brien TD, Reeves ND, Baltzopoulos V, Jones DA, Maganaris CN (2010) Mechanical properties of the patellar tendon in adults and children. J Biomech 43(6):1190-5. doi:10.1016/j. jbiomech.2009.11.028

34. Hovelius L, Lind B, Thorling J (1983) Primary dislocation of the shoulder. Factors affecting the two-year prognosis. Clin Orthop Relat Res 176:181-5

35. Yamamoto N, Muraki T, Sperling JW, Steinmann SP, Itoi E et al (2013) Does the "bumper" created during Bankart repair contribute to shoulder stability? J Should Elbow Surg 22(6):828-34. doi:10.1016/j.jse.2012.08.010

36. Phillips BB (2013) Arthroscopy of the upper extremity. In: Canale ST, Beaty JH (eds) Campbell's operative orthopaedics. Elsevier, Philadelphia, pp 2467-2557

37. Gerber C, Nyffeler RW (2002) Classification of glenohumeral joint instability. Clin Orthop Relat Res 400:65-76 